\title{
Research on Career Planning of College Students
}

\author{
Yanjun Luo \\ Students Safety and Life Service Center, Bohai University, Jinzhou, 121013, China \\ luoyanjun5885@163.com
}

Keywords: college students; career planning; research; planning process; planning table

\begin{abstract}
Do college students career planning, college students can fully know themselves and objective analysis environment, on the basis of planning the best career goals and route, promotes student's core competitiveness, to provide all-round development. In this paper, in accordance with the self- cognition, environment analysis, SWOT analysis, career decision-making, target decomposition, assessment and adjustment process of building the career planning process diagram, and a brief description of the various steps; Design the career planning book, can provide reference for students' career planning. Career planning is a systems engineering, the actual career planning, to give full play to the role of the government, school, family and students, realize the career development.
\end{abstract}

\section{Introduction}

Career is one of the professional experience, and it refers to a person in his life, all associated with occupational behaviors and activities, and related attitudes, values, aspiration for continuity of experience, is also a person life career and the change of position and work, the realization of the ideal process. Career is a dynamic process, is not included in the professional success or not, each working people have their own career.

Career planning means personal career choice of subjective and objective factors analysis and determination, determining personal goals and try to achieve this goal. Career planning requirements according to their own interest, characteristics, it will position itself in a most can play to their strengths, ability to select the most suitable for their career. Professional positioning is the key to the success or failure of the career, at the same time also is the starting point of the career planning. Career planning refers to a person in his whole life to take positions in succession process of forecast and plan, including a person's study, productive contribution to a career or organization and eventually retired. Individual career planning is not a simple concept, and there is a close relationship among it and the individual family and social organization. As individual values, family environment, work environment and the change of social environment, everyone's career aspirations are big or small change, so it is a process of dynamic change. Career planning is a system engineering, need to plan in time, and in the process of implementing constantly adjusted, so as to realize the smooth employment of personal [1].

The meaning of college students' career planning for college students development[2] : help students clear goals in life and career ideal, career ideal is from personnel of course of study in career goals, is a professional type, and professional aspects of the pursuit and yearning. Professional ideal implementation need to subjective factors of the objective conditions, only when the ideal and the reality is consistent, professional ideal will become a reality; Help students build a quality knowledge structure and improve the overall quality of knowledge accumulation is the foundation of success and necessary conditions of college students can be more rational understanding of self and knowledge society, make oneself personality constantly improve, finally realizes the unity of personal value and social value; Help students correct positioning, reasonable arrangement of study at the university of life, only the correct view of oneself and according to their own characteristics, the planning of university life, carry forward the advantage, make up the insufficient, especially the development of individual potential, to maximize the interests of the individual; Help students improve their vocational quality and sets up the correct choosing profession idea, college students should understand the social demand of different professions, 
analysis of economic conditions and social relations, according to their own advantage, develop appropriate career goals, choose more suitable jobs; Help college students to participate in social competition, college graduates in the talent market gradually become more abundant resources, China's large-scale adjustment of industrial structure, administrative departments, institutions and the phenomenon such as restructuring, require full career planning of college students.

\section{Process on Career Planning}

Career planning process is usually divided into six steps, as shown in Fig.1.

For as shown in Fig.1 career planning and the steps described as follows:

(1) Self cognition, it is to its own insight and understanding, including observation and self-evaluation. Self-observation refers to your awareness in aspects of perception, thought and intention; Self-assessment refers to his own thoughts, expectations, behavior and personality characteristics of the judgment and evaluation, it is the important condition of self-regulation. A man can succeed, lies not in what he has superior conditions, but in how he know his own self and how to use these conditions. In this competitive society to survive and grow, wants to be able to clearly know yourself first. Scientific and objective self-awareness is the premise of college students' career planning [3].At present, many college students lack of self-knowledge, main reason is the way of self-single and content is not comprehensive. Through the analysis of the comprehensive evaluation of self-knowledge, objective clearly recognize the existing advantages and disadvantages of itself and to plan their own career with the direction of the more accurate grasp. In the current study and the future work, avoiding disadvantages, strive for the early realization of their own planning objectives.

(2) Environmental analysis. Mainly is to analyze the various environmental impacts on career development. Everyone is in a certain environment, leaving the environment could not survive and develop. Therefore, when making personal career planning, to analyze the characteristics of environmental conditions, the development and change of the environment, their status in this environment, the environment for their request and environment may bring to their help, etc. Only fully understand the environmental factors, can achieve the disadvantages in the complex environment, solve the problem of "environment support me to do", make career planning has more practical meaning.

(3) The SWOT analysis of SWOT analysis. Based on internal and external competition environment and competition under the condition of situational analysis, is closely related to the object of study of various main internal strengths, weaknesses and external opportunities and threats, and so on, through the investigation list, and according to the matrix form, and then use the thought of system analysis, the various factors each other match analysis, from which a series of corresponding conclusions, and the conclusion is usually a certain decision-making. Career planning as today's college students enter the society of a kind of self-knowledge and self-prediction for future career, there is also the advantages and disadvantages of internal and facing the opportunities and threats, SWOT analytical method can be applied to the analysis on the college students' career planning, to achieve the comprehensive understanding of the current situation of college students' professional planning and characteristics of [4].

(4) The Career decision-making Career decision - making. Is a leading part of career planning, policy making, and the feasibility of it or not, directly determines the success of career planning. Wish (hope) to get the most ideal career development goals, you need to seriously to completely analyze yourself, know what I want, this life what he should get in this society, it is the need to seriously develop the career decision-making. And these only their most clearly, only their most understand yourself, and worked out the most appropriate decision goal. Develop career decision-making needs to combine their own personality, skills and interests; Take into account the actual situation, and has the enforceability; Career decision-making must be sustainable. Career decision-making will not be able to make a phased target, should be a series of can, through their whole career development career prospects. If career decision-making of short-term, behind and 
subsequent career decision point supports, will certainly make people lose struggle of passion, and not conducive to their long-term development.

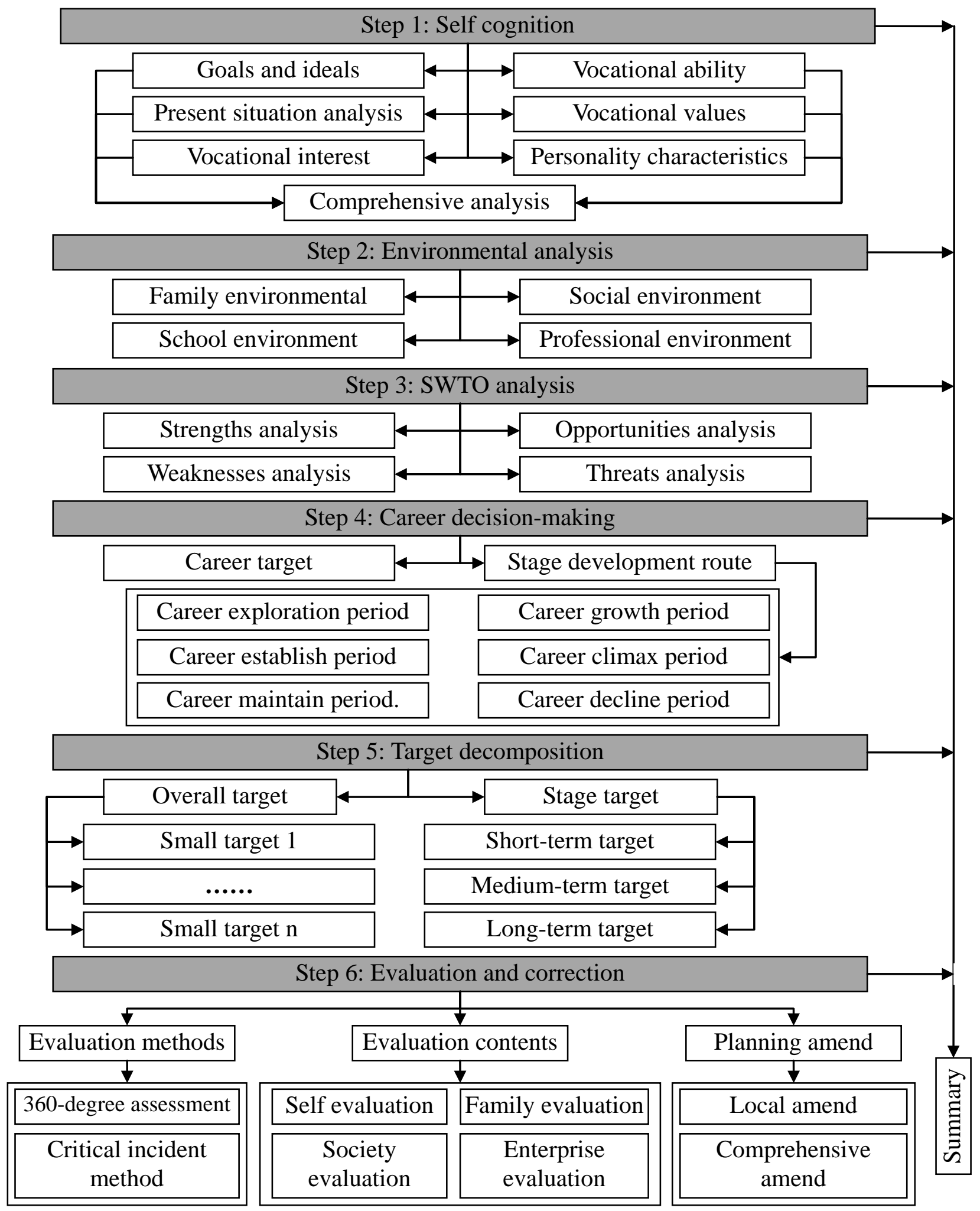

Fig. 1. Process on career planning

(5) The Target decomposition Target decomposition [5].On the basis of ERG theory, Yale University Clayton. Alderfer in Maslow's hierarchy of needs theory, on the basis of the closer to the practical experience of the research, this paper proposes a new humanism needs theory. Alderfer think, people there are three kinds of core, Existence needs, Relatedness needs, and Growth needs, thus the theory called "ERG" theory. Existence needs related to people's basic material and survival 
needs, including Maslow proposed physiological and safety needs; Relatedness needs refers to the people to keep important interpersonal demands, the satisfaction of the needs of the social and the position is in the interaction with other need to achieve, and Maslow's social needs and esteem needs the external part of the corresponding classification; Alderfer independence Growth needs, said personal development intrinsic desire, including the inner part of Maslow's self-esteem need classification and self-realization hierarchy contains features.

(6) Evaluation and correction Evaluation and correction [7]. Career need to be adapted to the external environment of adjustment and revision. Especially in the dynamic changes of the environment and individual inherent state of volatile ups and downs in the process of continuously, individuals need to evaluate their own career choices, career goals, route suitable for their own development, determine whether or not the right choice for the external environment change and sometimes seem out of place. Therefore, to make effective career planning, it requires ongoing evaluation and revision. At the same time, the individual's perception of self is constantly changing and increasingly mature, as individuals age, interests, abilities and experience is also changing, such as the professional orientation and judgment is also changing., most of the students choose a career for the first time, the success rate is not high, usually in a period of time in the career change, or adjustment, make it more in line with their own development. The choice of career routes, the correction of a goal in life is accompanied by individual growing and then feedback, assessment and correction, this kind of evaluation and feedback throughout the whole course of his career, make it more conforms to the long-term development of the individual, more conducive to a people gathered intelligence advantage, achieve success in the workplace.

\section{Career Planning Book}

Career planning book is written form content of career planning, planning content and the results in writing or in the process of planning the planning scheme, to help straighten out planning, provide operating instructions. Career planning book format a variety of simple format as shown in table 1. 
Table 1. Logical Structure Design on customer relationship management system

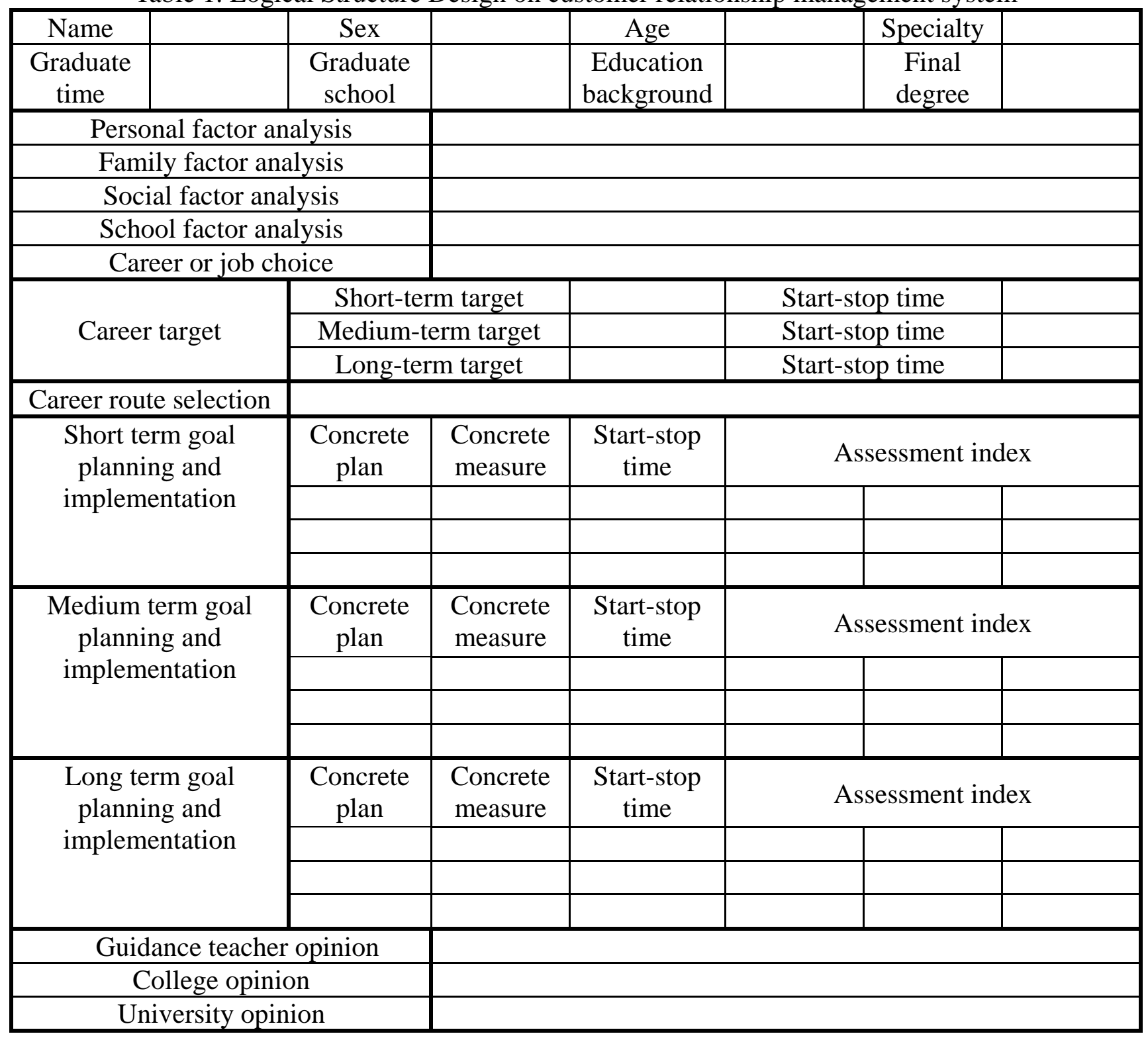

\section{Conclusion}

Career spanning the life most precious energy during prime time, everyone wants from the rigors of the career growth and development. College students who not enter the workplace, through career planning, can make their learning and life work in clear directions, and around the direction, make full use of good university life, constantly play to their potential, to achieve your goals. Practical career planning giving full play to the role of government, school, family and student[7-10]. The government should carry out a career planning and promoting the development of career planning. By related policies and documents, and promote the career planning and implementation and with money and other preferential policies to ensure the smooth progress of career planning. Schools, to strengthen the career planning education in the school, including strengthen ideological cognition, perfect the career planning education, strengthening the construction of teaching staff, training experts vocational guidance of teachers, improve the college students' career planning management system; Family, give full play to the role of the family, alleviate employment pressure, positive attention employment situation, reasonable guidance and to avoid excessive intervention. Parents play a model role, guide the children to work a correct understanding of everything from set out actually, constantly improve their own quality; The cultivation of the student, the student own core 
competence is an important pillar of career planning goals, strengthen the ability and the consciousness of the career planning, including strengthening self-awareness and career awareness, career planning awareness and ability, and establish the correct career goal, take an active part in social practice and training, etc.

\section{References}

[1] X. L. Li. Yang, "The influence of career planning of college students on the employment of college students," Contemporary Education Research and Teaching Practice, vol. 4, no. 6, pp. 104, 2016.

[2] J. Liu, "Analysis of contemporary college students' occupation career planning," Master's degree of Southwestern University, 2012.

[3] B. C. Wang, "An analysis of the factors of self - cognition in college students' career planning," Human resources development, vol. 7, no. 6, pp. 80-82, 2009.

[4] J. Liu, " SWOT analysis and countermeasures of college students' career planning," Course Education Research, vol. 2, no. 17, pp. 12, 2013.

[5] Y. Gao, "Career planning and management and the analysis of college students' career planning books," Chinese \& Foreign Entrepreneurs, vol. 30, no. 17, pp. 112-113, 2016.

[6] Department of enrollment and employment service, "Evaluation and feedback of career planning," http://zsjy.nuc.edu.cn/zls/Print.asp?ArticleID=1735, 2016-6-23.

[7] J. Zhang, "A Study of College Students' Career Planning," Master's degree of YanAan University, 2013.

[8] C. X. Zhu, L. B. Zhao, "Current situation and countermeasures of college students' career planning," Journal of Liaoning University of Technology (Social Science Edition), vol. 18, no. 3, pp. 82-85, 2016.

[9] J. Wang, "Research on the current situation and countermeasures of college students' career planning," Ability and Wisdom, vol. 16, no. 15, pp. 88, 2016.

[10] Z. W. Qu, L. F. Dong, Z. T. Zhao, L. K. Zhang, "Student Career Planning Problems and Their Countermeasures in Colleges and Universities," Journal of Shenyang Agricultural University(Social Sciences Edition), vol. 17, no. 4, pp. 428-433, 2015. 